\title{
Anàlisi de l'obra de José María Cagigal en relació amb el concepte de dona i la seva inclusió en l'esport
}

\author{
A Study of Work by José Maria Cagigal in Relation to the Concept of Women \\ and Their Inclusion in Sport
}

GONZALO RAMÍREZ MACÍAS JOAQUÍN PIEDRA DE LA CUADRA

Facultat de Ciències de l'Educació

Universidad de Sevilla
Autor per a la correspondència

Gonzalo Ramírez Macías

grm@us.es

\section{Resum}

Cagigal ha estat l'intel·lectual més rellevant i decisiu dins l'educació física i l'esport a Espanya. En aquesta investigació s'analitza la seva obra intel-lectual en relació amb el concepte de dona i el seu paper dins l'esport. Els resultats mostren que, encara sent un home del seu temps, en què els estereotips de gènere estaven ben assentats, va saber o va voler evolucionar en els seus últims anys cap a una posició de respecte envers el sexe femení i envers la seva inclusió en igualtat de condicions dins el camp esportiu.

Paraules clau: Cagigal, dona, esport, estereotips

\begin{abstract}
A study of Work by José María Cagigal in Relation to the Concept of Women and Their Inclusion in Sport

Cagigal was the most important and decisive intellectual in physical and sports education in Spain. This research studies his intellectual work on the concept of women and their role in sport. The results show that, while being a man of his time when gender stereotypes were well established, he knew and/or wanted to evolve in his last years towards a position of respect for the female sex and towards their inclusion, on equal terms, in the field of sport.
\end{abstract}

Keywords: Cagigal, women, sport, stereotypes

\section{Introducció}

La societat occidental, malgrat els seus grans avenços socioculturals, els quals han contribuït, majoritàriament, a augmentar la qualitat de vida dels homes i dones que en formen part, continua mantenint i generant actituds negatives sobre determinats col-lectius (com a exemples d'això es poden esmentar el racisme i la xenofòbia).

Un dels trets més arcaics i específics de les societats contemporànies occidentals és el seu caràcter patriarcal. En relació amb la dona, això s'ha traduït en la submissió en un paper secundari i adaptatiu, el qual l'home, des de la seva posició dominant, estableix en tots els estaments i organitzacions socials.

Aquesta situació ha estat especialment manifesta a Espanya, ja que durant la dictadura franquista, partint dels pressupostos promulgats i defensats pel Règim, l'Església i la Falange espanyola, es va incidir en gran manera en el sotmetiment femení. En el camp de l'educació física i l'esport, la Secció Femenina era l'encarregada de formar les dones espanyoles amb dos objectius: aconseguir una estètica corporal i desenvolupar una constitució física forta que els permetés engendrar i criar fills sans i robustos (Zagalaz, 2001).

No és fins als anys setanta que comença a sorgir a Espanya un moviment sociopolític d'alliberament de la dona que, encara avui dia, segueix vigent demandant independència, respecte a la idiosincràsia femenina i accés a tots els organismes i estaments socials en igualtat de condicions respecte al sexe masculí.

En el camp de l'educació física i l'esport, la dona d'avui dia no cerca la igualtat amb l'home, sinó la 


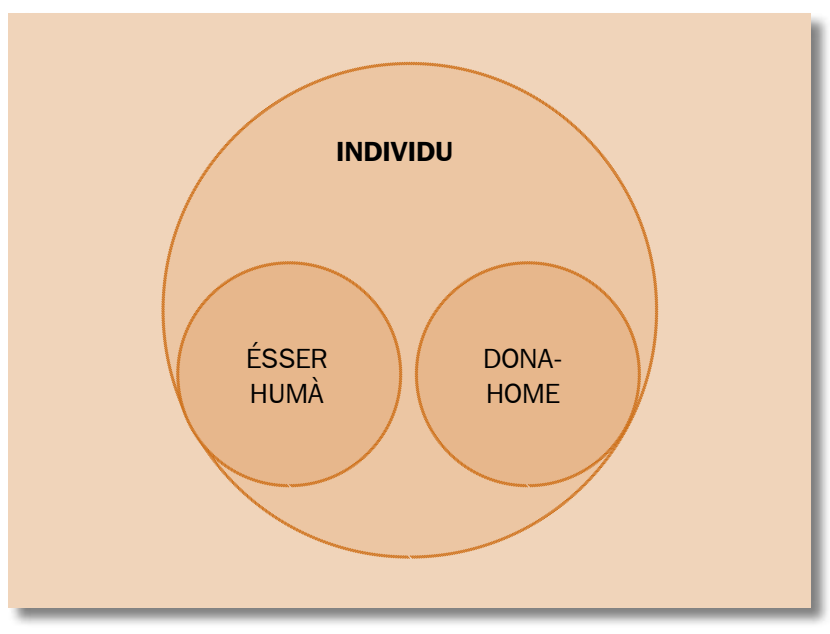

Concepció de l'individu segons José María Cagigal

definició d'un model corporal propi, autònom i respectat, amb les seves pròpies activitats fisicoesportives que parteixin de la seva mateixa naturalesa, que no s'hauria de comparar amb la masculina.

A partir d'aquest context, en constant evolució, cal preguntar-se per la visió i aportació respecte d'això del personatge més influent, determinant i clarivident d'aquest àmbit: José María Cagigal Gutiérrez.

Nombrosos són els estudis existents sobre Cagigal i la seva obra, molts dels quals conclouen que les seves aportacions continuen tenint vigència en l'àmbit de l'educació física i l'esport actuals.

Aquest intel-lectual, de reconegut prestigi no sols a Espanya sinó també a l'estranger, va ser molt prolífic quant a la seva producció intel·lectual (llibres, investigacions, conferències...). Així, Olivera (1997, p. 115), principal especialista sobre la figura de Cagigal, afirma que "va enregistrar 548 actuacions en distints mitjans de comunicació i a través de variades fórmules, la qual cosa equival a una mitjana de vint-i-una activitats intellectuals per any"*.

Els temes que va abordar en la seva vasta obra intellectual van des de l'esport (el més comú de tots aquests), l'educació física, l'oci o l'olimpisme, fins a la filosofia i la legislació. Un dels temes que va tractar de forma més superficial va ser el referit a la dona i l'esport. Respecte a aquesta temàtica, Olivera (1997) aporta diverses referències, dedicant fins i tot un epígraf dins la tercera part de l'obra José María Cagigal. El humanismo deportivo: una teoría sobre el hombre (publicada l'any 2003 en dos volums), dedicada a l'anàlisi de l'obra i el pensament d'aquest personatge. Les contribucions respecte d'això se centren en declaracions i aportacions fetes a la premsa escrita per Cagigal i en testimonis recollits de persones que van tenir tracte directe amb ell. Les conclusions d'aquesta anàlisi afirmen que la seva posició va ser canviant i bastant ambigua, amb un doble missatge: el públic i el privat.

Aquest caràcter d'ambigüitat i el context actual en relació amb la dona i l'esport ens va portar a plantejar aquesta investigació, l'objectiu de la qual és analitzar l'obra i el pensament de José María Cagigal, com a principal referent de l'educació física i l'esport a Espanya, en relació amb el concepte de dona i el seu paper dins l'esport. Per a això s'han utilitzat com a fonts de la investigació la col·lecció "José María Cagigal: Obras Selectas" (que inclou els seus vuit llibres més rellevants i un breu capítol titulat "La cultura física") i l'únic article trobat de Cagigal (no pertanyent a la premsa escrita) sobre la temàtica que ens ocupa, publicat en la revista Análisis e Investigaciones Culturales.

\section{Concepte home-dona}

Per José María Cagigal, l'ésser humà no era un ésser indiferenciat sinó un ésser sexuat. En la seva concepció de l'ésser humà, tota persona té dos plans diferenciats l'un de l'altre, però iguals. El pla home (persona humana) i el pla baró-femella. No es pot ser només "ésser humà" sense ser baró o dona.

El primer pla és el que dóna la major font de dignitat $i$ en aquest es troben els drets, els deures, l'accés al treball o a l'oci, i per tant, l'esport. El segon pla d'installació és la dualitat home-dona, que especifica cada individu en situacions i rols concrets: "La dona és primer ésser humà i després dona, encara que ambdues realitats no puguin separar-se sense risc d'abstracció. Conseqüentment, com a ésser humà és igual a l'ésser humàbaró" (Cagigal, 1982, p. 102).

Aquesta concepció portada a l'esport exigia la plena igualtat entre homes i dones, ja que els dos eren, abans que res, éssers humans: "La dona que fa esport és, primer que res, un ésser humà que assumeix aquesta conducta caracteritzada per esforç físic de tarannà lúdic, assumit amb més o menys opció competitiva [...] No es diferencia fonamentalment del baró-ésser humà que fa esport" (Cagigal, 1982, p. 103).

* NT: Les citacions d'aquest article s'han traduït del castellà. 
Les discrepàncies quant a la participació femenina en l'esport havien sorgit, segons ell, de la inseguretat del mateix baró, que no havia madurat i per tant tenia por de l'altre sexe. A això calia unir les diferències biològiques entre dones i homes que van propiciar posicionaments radicalitzats: "El conjunt dels estereotips tradicionalment dominants en la societat occidental i occidentalitzada podria resumir-se en l'esquema: home insegur - dona feble [...] L'esport, sobretot entès com a eficiència d'execucions físiques, es va anar configurant com una tasca típicament viril" (Cagigal, 1982, p. 109).

\section{Estereotips de gènere}

En el context històric en què José María Cagigal va desenvolupar els seus escrits, els estereotips de gènere estaven fortament arrelats en la societat espanyola. Una definició d'estereotips de gènere la trobem en l'obra de Barberá (2004), la qual afirma que són sistemes de creences sobre els grups d'homes i dones en general o sobre les característiques de masculinitat i feminitat per ells desenvolupades. Aquestes creences estan fortament arrelades en la consciència i escapen del control de la raó (Martín, 2006).

Per la societat franquista, el lloc de la dona era la llar, des d'on havia de difondre els valors i les pautes de comportament establerts criant $i$ educant els seus fills $i$ filles.

La masculinitat i la feminitat tenien les seves característiques clarament definides i diferenciades. La masculinitat havia de ser forta, agressiva, egoista... mentre que la feminitat era considerada fràgil, feble i silenciosa.

En les obres de Cagigal es troben un gran nombre de comentaris en què es reprodueixen els estereotips de gènere que imperaven. Així, respecte a la dona mestressa i mare, tenim: "Les nenes que juguen a nines o a botigueres són conscients que representen el paper de mares o mestresses o de botigueres" (Cagigal, 1996a, p. 30. Citació pertanyent a l'obra Hombres y Deporte, publicada per primera vegada l'any 1957). ${ }^{*}$

D'altra banda, defineix les dones com a persones inferiors, a les quals agrada fantasiar amb històries i somnis, evadint-se de la realitat amb facilitat:

Les nenes que juguen a "mares" amb les seves nines s'alliberen de les seves tristeses, de les seves estretors, de la seva pròpia petitesa i somien, creen fantàsticament, inauguren un món propi. Providencialment oxigenen els seus esperits, greixen bieles i cilindres per continuar rodant per la vida (Cagigal, 1996a, p. 254-255. Citació pertanyent a l'obra Deporte, Pedagogía y Humanismo, publicada per primera vegada l'any 1967).

"Les noies sobretot poden viure a soles amb els seus somnis enmig del món real en un notable grau d'aillament" (Cagigal, 1996a, p. 185. Citació pertanyent a l'obra Hombres y Deporte, publicada per primera vegada l'any 1957).

Quant a l'altre sexe, els estereotips lligats als homes són per Cagigal l'abrivament, la brutalitat, la duresa, l'agressivitat i l'autoritat. Aquestes característiques estan unides a la masculinitat, sigui en l'esport o en la vida quotidiana: "Era un desfogament espontani, primari, una mica animal, però també a la manera del baró." (Cagigal, 1996a, p. 182. Citació pertanyent a l'obra Hombres y Deporte, publicada per primera vegada l'any 1957) "Els instints agressius són més violents i necessaris en l'home que en la dona" (Cagigal, 1996a, p. 213. Citació pertanyent a l'obra Deporte, Pedagogía y Humanismo, publicada per primera vegada l'any 1967).

El valor ha estat objecte de llargs estudis. S'estableix robustament, igual que el to de decisió, [...] que la força autoritària, en la masculinitat. Sempre, en la història dels pobles, s'ha reservat als homes la funció de dirimir conteses. La fisonomia del jutge ideal ens assenyala la virilitat. Heus aquí un altre requisit de l'àrbitre (Cagigal, 1996a, p. 106. Citació pertanyent a l'obra Hombres y Deporte, publicada per primera vegada l'any 1957).

Aquestes diferències exposades per Cagigal estan basades, segons ell, en troballes d'investigacions científiques en el camp de la psicologia:

En la investigació esmentada anteriorment d'A. Prueske s'assenyala, en la setena conclusió: difereixen en el grau i tipus d'hostilitat d'home i dona. L'anàlisi de la variància va descobrir diferències significatives entre els sexes segons el Buss-Durkey Inventory. Els homes van donar un més alt nivell d'escales d'hostilitat física i verbal, mentre que les dones van manifestar més alts símptomes d'hostilitat indirecta (Cagigal, 1996c, p. 1155. Citació pertanyent a l'obra Deporte y agresión, publicada per primera vegada l'any 1976).

\footnotetext{
* Aquest tipus d'aclariments sobre l'obra específica de què es pren la citació literal s'inclouran al llarg de tot l'article, ja que és imprescindible per valorar l'evolució de l'obra cagigaliana amb relació al concepte de dona i la seva inclusió en el camp de l'esport.
} 


\section{Estereotips de gènere en l'esport}

Tal com s'ha exposat amb anterioritat, per Cagigal hi ha uns trets femenins i uns trets masculins, i per tant és fàcil pensar que l'esport es veu influenciat per aquests trets o estereotips. En analitzar les obres d'aquest intel·lectual es poden obtenir les conclusions següents respecte d'això: hi ha esports masculins i esports femenins, esports que potencien la virilitat dels homes i que per tant no són permesos a les dones, i esports que desenvolupen la feminitat i que no són practicats pels homes.

Entre els esports masculins esmentats per Cagigal trobem la pilota basca, que defineix com "un esport amb un cert estil cavalleresc, en el qual la contesa és exhaustiva i respectuosa [...]. És robust, dur, vigorós, de vegades terrible [...]. És un esport fisiològicament complet." (1996b, p. 531. Citació pertanyent a l'obra Deporte, pulso de nuestro tiempo, publicada per primera vegada l'any 1972) Per l'autor, la pilota basca potencia la virilitat i enriqueix l'home: "La pilota basca [...] és enèrgica, d'una esplendorosa virilitat." (Cagigal, 1996a, p. 213. Citació pertanyent a l'obra Hombres y Deporte, publicada per primera vegada l'any 1957).

En la conjuntura antropològica bisexual en què vivim -sigui per molts segles-, tot el que fomenti la virilitat en l'home i la feminitat en la dona ha de ser ben acollit i acuradament conreat. Heus aquí un esport netament viril [la pilota basca], i per això humanament enriquidor. (La modalitat femenina de raqueta no passa de ser una resposta imitativa suavitzada d'un esport essencialment masculí) (Cagigal, 1996b, p. 532. Citació pertanyent a l'obra Deporte, pulso de nuestro tiempo, publicada per primera vegada l'any 1972).

Basant-se també en estudis precedents, estableix que els jocs de pilota practicats amb les mans són preferits per les nenes, mentre que els preferits pels nens són els practicats amb els peus. Per ell, donar un cop amb el peu és una acció de caràcter primari, més agressiu i per tant masculí.

El fet que hi hagi esports com el rugbi, el beisbol o el criquet, totalment virils, consistents a agafar o llançar, indica la fàcil masculinització d'aquestes actituds; no obstant això, no hi ha cap esport en què l'acte de copejar amb el peu es feminitzi (Cagigal, 1996a, p. 214. Citació pertanyent a l'obra Hombres y Deporte, publicada per primera vegada l'any 1957).
En definitiva, tots els esports en què la duresa $\mathrm{i}$ l'agressivitat són intrínseques (futbol, boxa, rugbi) estan prohibits per a les dones. Fins i tot dins un esport en un principi neutre com és l'atletisme, hi ha especialitats que són masculines:

La duresa muscular no convé a la dona. En l'home es pot admetre. L'elasticitat, ritme, flexibilitat, harmonia, convenen a ambdós. La dona té vedats, en el camp esportiu, a banda d'altres excepcions específiques, els jocs on siguin presents la violència i la duresa. Per això se li recomana especialment aquests altres. La qual cosa no significa que amb aquesta arribada femenina queden desnonades per al sexe fort [...]. El més robust, el més típicament viril, en l'atletisme, són els llançaments (Cagigal, 1996a, p. 212. Citació pertanyent a l'obra Hombres y Deporte, publicada per primera vegada l'any 1957).

Existeixen també esports o activitats físiques més adequades per a les dones que per als homes. Com s'ha vist anteriorment, aquelles activitats que desenvolupin els sentiments, l'expressió, l'espontaneïtat, el ritme, la flexibilitat són considerades femenines per Cagigal: "Sabut és també l'influx que els exercicis rítmics exerceixen en el sentiment. D'aquí deriva el fet que s'hagi admès com definitiva per a la dona la gimnàstica cal-listènica." (Cagigal, 1996a, p. 211. Citació pertanyent a l'obra Hombres y Deporte, publicada per primera vegada l'any 1957).

Finalment, cal indicar que, a vegades, l'adjectiu $f e-$ mení pren un caire despectiu que s'usa per insultar o ridiculitzar una activitat masculina o neutra:

S'ha dit que el basquetbol és un esport femení. $\mathrm{Si}$ s'entén que les seves condicions internes són útils per a la dona, pot acceptar-se l'expressió. Però el sentit pejoratiu d'exclusivitat femenina, a la manera dels jocs de nines en la infància, és ridícul [...] Resulta absurd titllar de femení el basquetbol perquè és rítmic, elàstic, flexible i elegant (Cagigal, 1996a, p. 212. Citació pertanyent a l'obra Hombres y Deporte, publicada per primera vegada l'any 1957).

\section{Esportistes utilitzats per il-Iustrar}

A més de les teories i idees desenvolupades i explicitades per José María Cagigal en la seva obra, és interessant, des del punt de vista de la perspectiva de gènere, analitzar el que en educació es coneix com a currículum ocult. Santos (2000) defineix el currículum 
ocult com el conjunt de normes, actituds, expectatives, creences i pràctiques que s'instal-len de forma inconscient en les estructures i el funcionament de les institucions i en l'establiment i desenvolupament de la cultura hegemònica d'aquestes. A l'obra de Cagigal podem analitzar els esportistes amb què va exemplificant i illustrant les seves idees. Trobem un total de 173 esportistes de diferents esports i de diferents èpoques presents a les seves obres, i de tots ells 18 són esportistes dones, la qual cosa suposa únicament el $10 \%$ de les mencions. Aquesta baixa presència de dones esportistes suposa la no existència de referents femenins importants en l'esport o el fet que els que existeixen no són rellevants.

De les esportistes mencionades, la majoria practiquen esports catalogats per Cagigal com a femenins, per exemple l'atletisme (5), la natació (4), la gimnàstica (3), el tennis (3) i l'esquí (1).

La presència de la dona en l'esport ha de ser estudiada principalment en l'àmbit on s'ha produït una conquesta majoritària. Això succeeix en una gran quantitat de modalitats esportives, com per exemple natació, atletisme, basquetbol, hoquei, handbol, gimnàstica, patinatge, esquí, judo, tennis, golf, etc. (Cagigal, 1982, p. 104).

Els esportistes masculins utilitzats per exemplificar les teories cagigalianes, a més de ser més nombrosos, es refereixen a moltes més modalitats esportives que en el cas de les dones, i es comptabilitza un mínim d'onze d'aquestes modalitats.

\section{Evolució de Cagigal respecte a la dona i l'esport}

Són molts els comentaris i estereotips sexistes que es poden observar en l'obra de José María Cagigal. Els seus primers escrits de finals de la dècada dels anys cinquanta i principi dels seixanta, pertanyents al que Olivera (2006) ha denominat etapa religiosopedagògica, estan infestats d'afirmacions i exemplificacions moltes vegades innocents però que no feien sinó perpetuar els estereotips sexistes de la societat en què li va tocar viure. En els següents assajos escrits a finals dels seixanta i la dècada dels setanta (etapa de transició o filosoficocientífica), continuen apareixent en gran quantitat exemplificacions sexistes en què s'ubica les nenes i les dones en aquells rols assignats per la societat com a femenins i els nens i els homes executant els rols masculins establerts: "Dos nens que corren, una nena que vesteix la seva nina com si fos la seva filla." (Cagigal, 1996a, p. 276. Citació pertanyent a l'obra Deporte, Pedagogía y Humanismo, publicada per primera vegada l'any 1967)

No obstant això, en els seus últims escrits, pertanyents a l'etapa filosoficosociològica, és possible observar un canvi; és en aquesta última etapa, de principi dels anys vuitanta, que trobem el nombre més gran d'exemplificacions femenines. A més a més, en les seves publicacions de 1981 (Deporte, espectáculo y acción i iOh deporte! Anatomía de un gigante) trobem dos textos que tracten explícitament el tema de la dona en l'esport. En aquests defensa les bondats de la pràctica esportiva per a la dona, fins i tot en períodes vitals en què estava mal vist, com és el cas de l'embaràs:

En la nostra època, no existeix encara la igualtat d'oportunitats d'ambdós sexes en la pràctica esportiva. Molts continuen pensant que certes circumstàncies de la vida de la dona li impedeixen (o almenys li dificulten) la pràctica de l'esport, però això no és cert. S'ha demostrat, per exemple, que la menstruació no sols no impedeix l'activitat esportiva, sinó que les molèsties menstruals sembla que són menors en les dones esportistes. I el mateix ocorre amb l'embaràs (encara que hi ha certs esports que s'han d'evitar en aquesta etapa) i la menopausa, en la qual resulta molt útil un exercici equilibrat que evita problemes tant d'índole física com psíquica (Cagigal, 1996c, p. 850. Citació pertanyent a l'obra Deporte, espectáculo y acción, publicada per primera vegada l'any 1981).

És en aquests assajos en què desenvolupa la seva idea d'ésser humà com a ésser bipolar, amb dos plans diferenciats però iguals, reconeix les diferències entre dones i homes però les adjectiva com a enriquidores tant per a l'home com per a la dona. En el llibre ;Oh deporte! Anatomía de un gigante (1981), en l'apartat "Mujer y Deporte", també publicat el 1982 en la revista Análisis e Investigaciones Culturales, Cagigal analitza les diferències que els estudiosos havien trobat entre homes $\mathrm{i}$ dones i fa ressaltar els conflictes d'autoidentificació de les dones esportistes, ja que no coincideixen amb els rols femenins de la societat.

Cagigal critica l'esport que cerca el rècord com a masculinitzat. Segons la seva opinió, dones i homes no han de competir entre ells, perquè les diferències corporals a favor dels barons faria impossible tenir una competició equitativa. Exhorta a una pràctica no competitiva, que permeti la millora de la qualitat de vida: 
Dins els actuals programes de defensa de la qualitat de vida, està la recuperació de les singulars qualitats humanes de l'esport, molt més fondes, riques, fecundes que els simples resultats competitius. En aquesta línia toca a la dona una important tasca; com toca a l'home (Cagigal, 1996c, p. 1023. Citació pertanyent a l'obra ;Oh deporte! Anatomía de un gigante, publicada per primera vegada l'any 1981).

\section{Conclusions}

L'esport, des del seu inici, ha estat un camp vedat per a la dona $i$ no ha estat fins a mitjan segle $x x$ que aquesta ha anat obrint-se pas, de forma lenta i progressiva, dins aquest. Molts grans dirigents i intel-lectuals de l'esport es van oposar frontalment a la incorporació de les dones; serveixi com a exemple paradigmàtic el baró Pierre de Coubertain.

El gran intel-lectual de l'educació física i l'esport a Espanya durant l'últim segle va ser José María Cagigal, home educat en el si d'una família cristiana d'arrelats valors tradicionals, amb una sòlida formació clàssica $i$ una profunda fe religiosa. Aquest context li va influir notablement, com a qualsevol persona, en relació amb la seva visió de la dona, de manera que donava per fets molts estereotips generats en el context masclista i arcaic que va ser la dictadura franquista. Possiblement, durant molts anys, no va arribar ni tan sols a plantejar-se que poguessin ser d'una altra forma.

No obstant això, la clarividència per la qual destaca tota la seva obra també va tenir el seu reflex en relació amb la incorporació de la dona a l'àmbit esportiu. Com ja ha estat descrit, aquest intel-lectual va evolucionar des de posicions clarament influenciades per estereotips masclistes, cap a posicions de respecte envers el sexe femení. Coincidim amb Olivera (2003) en afirmar que Cagigal, en la seva última època (dècada dels anys vuitanta), experimenta una notable evolució al fil dels temps, ja que es dedica a explicar les causes del retard esportiu femení més que a manifestar les limitacions en la seva pràctica (aspecte en què va insistir durant els anys seixanta i setanta). Tot això potser es va deure a la influència rebuda dels moviments feministes i contraculturals de l'època, que promulgaven la integració total de la dona en la societat.

Finalment, avui dia es demanda socialment el dret a la diferència; la dona no vol comparar-se amb l'home, ni practicar els mateixos esports, sinó que cerca el respecte a les seves pròpies pràctiques, emanades del seu propi model esportiu. Aquesta idea ja germinava en les últimes obres de Cagigal, on defensava la igualtat d'homes i dones, ja que els dos són éssers humans independentment del seu sexe, considerant les diferències entre homes i dones com a aspectes enriquidors per a ambdós sexes.

\section{Referències}

Barberá, E. (2004). Perspectiva socio-cognitiva: estereotipos y esquemas de género. A E. Barberá i I. Martínez (Comps.), Psicología y género (pp. 55-80). Madrid: Pearson Educación.

Cagigal, J. M. ${ }^{\text {a }}$ (1982). Mujer y deporte (Un apunte de antropología cultural). Análisis e Investigaciones Culturales (11), 101-112.

Cagigal, J. M. a (1996a). Obras selectas (Volum I). Cádiz: COE, Ente de promoción deportiva "José María Cagigal”, Asociación Española de Deportes para Todos.

Cagigal, J. M. ${ }^{\text {a }}$ (1996b). Obras selectas (Volum II). Cádiz: COE, Ente de promoción deportiva "José María Cagigal”, Asociación Española de Deportes para Todos.

Cagigal, J. M. ${ }^{\text {a }}$ (1996c). Obras selectas (Volum III). Cádiz: COE, Ente de promoción deportiva "José María Cagigal”, Asociación Española de Deportes para Todos

Martín, A. (2006). Antropología de género. Culturas, mitos y estereotipos sexuales. Madrid: Cátedra.

Olivera, J. (1997). Glossa de José María Cagigal (1928-1983): un intel·lectual en acció Apunts. Educació Física i Esports (47), 113117.

Olivera, J. (2003). José María Cagigal. El humanismo deportivo: una teoría sobre el hombre (Volum 2). Málaga: Instituto Andaluz del Deporte, Junta de Andalucía.

Olivera, J. (2006). José María Cagigal y su contribución al humanismo deportivo. Revista Internacional de Sociología. RIS (44), 207-235.

Santos, M. A. (2000). Cambio cultural en la escuela que aprende. Perspectiva de género en la organización escolar. Recuperat de http://educacion.pnte.cfnavarra.es/portal/digitalAssets/2/2040_ genero.doc

Zagalaz, M. ${ }^{a}$ L. (2001). L'educació física femenina durant el franquisme. La secció femenina. Apunts. Educació Física i Esports (65), 6-16. 